\title{
An Evidence for Validity of Holland's Theory of Personality Types in Turkish Culture
}

\author{
Olcay Y1lmaz \\ Ufuk University, Ankara, Turkey
}

\begin{abstract}
In this research Holland's theory of personality types is tested in a Turkish sample, using Vocational Interest Inventory (VII) developed by Yilmaz (2011) on the basis of Holland's personality theory (1997). Research sample consisted of 2,241 working adults of a public organization in several different cities. As a result of the study, VII with 60 items in six scales is developed in accordance with Holland's personality types. Psychometric characteristics of the inventory proved that VII is a valid and reliable measuring tool. On a pictorial represantation with the use of the hexagonal model, inter-scale correlations were found almost matched as it is in Holland's personality theory. Even though some minor discrepancies with the theory were found in Social and Enterprising types, it might be concluded that Holland's theory is valid for the research sample.
\end{abstract}

Keywords: Holland, vocational preference, vocational interests, interest inventory

\section{Introduction}

Clients' need of a professional help is becoming much more essential day by day while ever-increasing vocational and educational requirements change vocational diversity. As Yeşilyaprak (2005) emphasized, every profession has its own opportunities and distinctive operating conditions. Such visually noticed differences among professions signify some psychological variations like ability, interest, and individual needs. Therefore it is vital for individuals to choose a profession which matches their needs and creates the opportunities to support their personal development. A sensible decision is only possible when one explores himself and his options in detail.

Even though there are various scientific approaches in career counseling, Holland's personality types theory is one of the most commonly used (Gottfredson, 1999). Holland's theory $(1973 ; 1985 ; 1997)$ is a comprehensively studied and affective vocational interest theory (Tracey ve Gupta, 2008). Strong Interest Inventory, Self Directed Search (SDS) and UNIACT are some of the many Holland' personality theory based questionnaires widely used in career counseling (Armstrong, Allison, \& Rounds, 2008). Main favourable aspect of this theory is that it is application oriented and has been revised repeatedly right from it was constituted (Gottfredson, 1999; McClain \& Reardon, 2015).

Other factors which made the theory so widespread are: the theory is commonly employed by many institute and organizations for vocational guidance (Laurence, 2004), it was reivewed and revised by the researcher in 1959, 1966, 1973, 1985 and 1997 with a support of more than 100 researches (Gottfredson, 1999), and it is quantitatively the most researched vocational preference theory (Harrington \& Feller, 2004).

Olcay Y1lmaz, Dr., Associate Professor, Department of Education, Ufuk University. 


\section{Holland's Theory of Personality Types}

Holland's theory is a combination of some basic ideas and sofisticated components of these ideas. First of all it pronounces that people may be classified in relation with their resemblence to one of the six personality types (Realistic, Investigative, Artistic, Social, Enterprising, Conventional). A person who resembles to a type will possibly act or behave similarly and will have similar personality characteristics. Moreover, the environment where people live and work may be identified with its resemblence to the same typological classification. And finally a characterization can be produced with the help of the data derieved from this person and environmental types' matching degree. This sort of characterizations may consist of issues such as vocational preference, vocational determination and achievement, self-efficiacy, social behaviours and sensibility to be affected (Holland, 1997).

\section{Interrelations of the Personality Types}

Interest inventories may be used to assess how much an individual has the characteristics of an identified personality type. An individual can be identified as fit to a certain personality type in accordance with his/her highest subscale score. A personality pattern can be obtained by arranging all the subscale scores from the highest to the lowest. Even though a personality pattern consists of all the six types, usually only first two or three of them are taken into consideration (Holland, 1997).

Holland's hexagonal model has two major components. Interests can be associated with a visualisation on a circular design and they correlate with each other (Tracey \& Rounds, 1995). It was proved for the first time in a research consisting 12,345 male and 7,968 female university students using Holland's Vocational Preference Inventory (VPI) that personality types have significant correlations and this finding may be demonstrated on a hexagon considering their divergence. The personality types and their correlations as the findings of the research are pictured in Figure1 (Holland, Whitney, Cole, \& Richards, 1969). As it is shown in the figure, correlations of the personality types and a comparison may be described on a hexagonal model. The closer the two types the more similar they are and they correlate more as well. For instance Realistic and Investigative types are close on the model and they have more in common in relation with the other types. On the contrary Realistic and Social types have the most possible distance and they have less in common and correlate less.

\section{Researcheson Cultural Validity of Holland's Personality Types Theory}

It is widely accepted that in many cultures dimension of interest inventories measures different attributes with a various sensitivity. There are many researches on this subject. Tracey and Rounds (1993) found that Holland's hexagonal model has a low fit rate among non-Americans and ethnic-Americans. Another study by same researchers in 1996 showed that regardless of the analysis type used, Holland's hexagonal model does not support intercultural struct validity. From this point of view, it may be construed that subscales may be measuring different constructs in various cultures with a diverse fit ratio (Tracey \& Gupta, 2008).

In fact when related researches are examined it is seen that there are various findings about Holland's RIASEC model's validity in different cultures. Various Holland's personality theory based researches (Darcy, 2005; Sverko \& Babarovic, 2006; Sverko, 2008; Hedrih, 2008; Tang, 2008; Nagy, Trautwein, \& Lüdtke, 2010) showed some firm proof on cultural validity in Ireland, Croatia, Serbia, China, and Germany. As it is easily noticed many of these countries may be regarded as reflecting western culture and have cultural similarities to U.S.A. where the theory has been grounded. Meanwhile researches in some countries (Mexico, Spanish Bask Region, Hong Kong, Philippines, India) which have relatively different cultural construct, reported partial 
validity (Farh, Leong, \& Law, 1998; Flores, Spanierman, Armstrong, \& Velez, 2006; Yang, Lance, \& Hui, 2006; Elosua, 2007; Primavera, Church, \& Katigbak, 2010). According to some researchers (Leong, Austin, Sekaran, \& Komarraju, 1998; Yanga, Stokesa, \& Hui, 2005) the reason behind low validity accounts for different job opportunities and vocational definitions by comparison to the norm countries. In another study by Gupta, Tracey, and Gore (2008) Holland's RIASEC model was analized amongst ethnic groups of U.S.A. and it was found that when using non-parametric methodology, the model showed some good match, whereas with structural equation modeling it has less validity. As researchers conluded, type of statistical methodology is influential besides different cultural constructs when identifying the validity.

There is sufficent research on validity of Holland's RIASEC based scales on U.S.A. citizens but there is a limited number of studies on U.S. ethnic groups and other countries to support this model (Tracey \& Rounds, 1995). In Turkish culture Holland's model was tested by Balkis (2004) in Self Directed Search's adaptation study to Turkish culture and it was concluded that RIASEC model may be considered as valid for Turkish culture. Yet considering this research's limited population there is still need of more studies to ensure Holland's personality types theory is valid in Turkish culture.

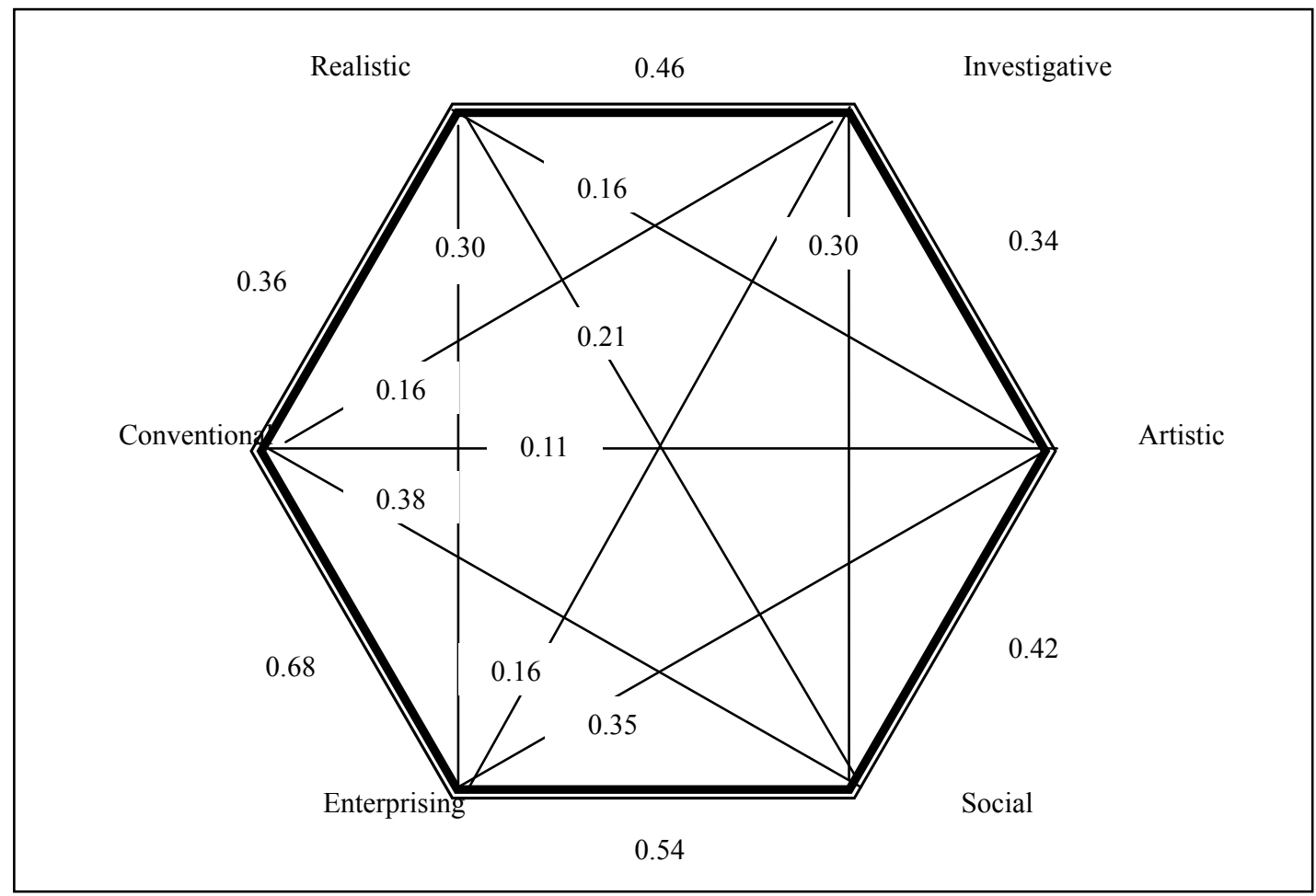

Figure 1. Personality types and their correlations (Holland, Whitney, Cole, \& Richards Jr., 1969).

\section{Method}

Even though there are plenty of researches world-wide on Holland's personality types theory the number is limited in Turkey (Ylldırım, 2001). In order to overcome this deficit, Yılmaz (2011) developed an interest inventory (Vocational Interest Inventory; VII) based on Holland's personality types. This research was aimed at providing a support for cultural validity of the theory beside being mainly a development of an interest inventory. Vocational Interest Inventory is developed on the basis of John L. Holland's personality types theory and subscales of VII is composed of these personality types. The sample was chosen from adult employees who 
had positions as to be managers, assistant managers and leaders working at schoolswhere the vocational trainings had been given. Vocational Interest Inventory was administered to 2,241 young and adult people who are between 22-55 years old in seven provinces and the number of female subjects was only $12(0.5 \%)$.

Items and the questionnaire forms developed by the researcher to be used in psychometric studies, are also trial form of the inventory and "Self-Assessment Inventory" which was developed by Kuzgun (1988) were used. Likert-type four point scale ( 1 = Strongly I do not like, 2 = I do not like, 3 = I like, 4 = I strongly like) was chosen for item responding.

In accordance with the stages of development of Vocational Interest Inventory, problem situation and the purpose of research, limitations resulting from the time and sampling adequacy were determined and taken into consideration. Also the development stages of similar scales (ASVAB Interest Inventory, O*NET Interest Inventory, Strong Interest Inventory) were examined and appropriate models were used.

\section{Reliability of VII}

Reliability of VII is determined by using internal consistency and test-retest reliability coefficients. The Cronbach- $\alpha$ coefficient, which is used to calculate the internal consistency of VII, was found 0.90 for the whole inventory and it was found between 0.71 (Social) and 0.87 (Investigative) for its dimensions. Additionally test-retest reliability coefficients of VII, obtained from 5 week interval two administrations on 90 people who were randomly picked up from the two different vocational schools, were found between 0.60 and 0.80 .

\section{Validity of VII}

In the scope of validity, the construct validity, face validity and inter-scale correlationsof the dimensions were examined. In the process of determining the construct validity of the scale, the exploratory and confirmatory factor analyses were used. With the exploratory factor analysis, determination of trial items was done, and with the confirmatory factor analysis, the validity of the Holland's theory was tested. Thus, data set obtained from the trial form was divided into two randomly chosen sets. With the first data set $(n=1,500)$ exploratory factor analysis was conducted by SPSS 15.0 (Statistical Package for Social Sciences for Social Sciences). On the other hand, with second data set $(n=741)$, confirmatory factor analysis was performed using LISREL 8.80 (Linear Structural Relations) statistical software.

As for the exploratory factor analysis, orthogonal rotation, varimax and principal components analaysis were used. The KMO value, which represents the adequacy of the sample size, was found 0.909. When Bartlett test results of the inventory had been examined, it was found that the obtained chi-square value was meaningful at 0.01 level. In the lights of all these findings, it was considered that the data structure is extremely convenient for factor analysis.

Due to the items and dimensions having been determined on the basis of Holland's personality theory, the number of factors used for the exploratory factor analysis was predefined as six to be in accordance with the theory. Appropriateness of such an approach was confirmed with factor eigenvalues, scree plot graphic and variances explained by the factors. It was seen that the eigenvalues of the first six factors were over the value one and there was a significant drop in the eigenvalues of the next factors coming after the first six ones. In addition to these findings, it was determined that the contribution of the eigenvalue to variance reduced starting from the seventh factor. Since the amount of change in eigenvalues were quite low as well in the scree plot graphic, the presence of a six factor structure was showed up. As a result of exploratory factor analysis, it was found that the first six factors were explaining the $\% 42,315$ of the total variance. When item-factor loadings 
were examined, it was found that they varied between 0.359 and 0.729 . In case the findings related to the confirmatory factor, analysis is evaluated as it is being in accordance with the measurements (Tabachnick \& Fidel, 2001; Schermelleh-Engel1, Moosbrugger, \& Müler, 2003; Şimşek, 2007; Çokluk, Şekercioğlu, \& Büyüköztürk, 2010) determined in literature. It can be said that the model associated with the items and dimensions of the inventory is having satisfactory fit with the aspect of explanation of the implicit and obvious variables' relation, good fit when considering the $t$-values and error variances, medium level fit in terms of the some of the compatibility statistics while showing low fit values in terms of the others.

As for the face validity, opinions of eight experts were taken, two of them during item development phase and six of them before administering the trial form. The trial form was created, as a result of the feedback of the experts and pilot trial.

As a further evidence for the validity of the inventory, inter-scale correlation values of the dimensions were calculated. As it was stated above before, one of the most important premises of Holland's personality theory is that the personality types can be displayed on a hexagonal pattern depending on the relation between dimensions. The appropriateness of the divergence of the types to the model of Holland was examined by using the total scores of individuals collected for the each dimension of the Vocational Interest Inventory.

Finally, considering the fact that it was designed as an inspiration of Holland's theory (Kuzgun, 2003) and the applied subscales were showing parallelism with the personality types of Holland's theory (Özyürek, 1996; Y1ldırım, 2001; Kuzgun, 2003), the Self Assesment Inventory (SAI), which was developed by Kuzgun (1988), was used to support parallel forms validity. At this stage, VII and SAI were administered together to a 82 people sample and the scores received from each administration were compared. In conclusion, it was observed that there is a meaningful statistical and theoretical relationship between the measurement values of VII and SAI considering their scope of dimensions and contents even if they do not have exactly the same structure.

Findings Regarding the Validity of Holland's Theory on Turkish Culture

\section{Structure of Personality Types}

One of the significant findings obtained from the exploratory factor analysis of VII is related with the items excluded from the inventory since they showed (overlap) factor loadingsin more than one dimension. When the contents of these excluded items were examined, it was understood that some of the items related with the "helping activities" which is one of the characteristics of social personality type were showing overlaps. As an example, items like "helping old people in their daily works" were excluded from the trial version of the inventory since they showed very close item-factor loadings in multiple-dimensions.

It is considered that the structure of Turkish culture plays a significant role for this finding. In Turkey, whatever the personality types and professions of individuals are, helping to deprived people is a common cultural value. Indeed, Kuzgun (2003) touched upon the similar findings for the "Social Help" dimension of SAI and also stated that this property was sometimes examined under the heading of "values" instead of "interests" among the studies in literature.

It was thought that another explanation for this finding about "Helping activities" items can be arisen from the homogeneity of the sample. Even though there are individual differences among the sample in terms of the area of professions, they are much homogeneous when their genders and values are considered. It was concluded that people with similar values may have responded these items by the light of not only their interest but also their values. 
When mean score distributions of dimensions were examined, it was brought into view that there are findings supporting this inference. It was determined that the highest mean score belongs to the items of the Social type and other mean scores are listed respectively as Enterprising, Investigative, Realistic, Conventional, and Artistic types. This order can be explained by the fact that when compared to the other types, Social and Enterprising types contains more items which are more likely open to social desirability. Individuals responding the questions of the inventory could give subjective answers in the fields of training, leadership, persuasion and interpersonal relations to receive the appreciation of the researcher. However, if daily working lives of the research sample are considered, this finding may also show the real results at the same time. Since, the majority of these people are performing the activities of Social and Enterprising types as a requirement of their vocational environments and they are not usually performing independent and artistic activities of Artistic type.

\section{Interrelations Between Personality Types}

While defining the interest patterns of the individuals with six basic personality types, Holland also showed the interrelations between these personality types on a hexagonal pattern. One of the basic assumptions of the theory is its structure with a significant relationship between each of the six basic personality types. According to this model, one of the personality types shows highest rate correlation with its adjacent type and shows lower correlation with the more distant ones (Reardon \& Lenz, 1999). As a result, because of its position in the pattern, it is expected that individuals matching Realistic personality type, will show high correlation with Investigative and Conservative types and show low correlation with the others.

Using the data obtained in the development phase of the Vocational Interest Inventory, the validity of Holland's theory on the sample was also tested. For this purpose, two separate sets of data were used in exploratory and confirmatory factor analyses and interrelations between the dimensions of inventory was analized. With the first data set, the total scores for each dimension of the individuals were calculated in accordance with the determined factor structures and relation between dimensions was examined (Table 1). Between all dimensions, significant $(p<0.01)$ correlations were found as being appropriate to the Holland's hexagonal model.

Table 1

Pearson Correlation Coefficients Between the Dimensions of First Data Set

\begin{tabular}{lllllll}
\hline & Realistic & Investigative & Artistic & Social & Enterprising & Conventional \\
\hline Realistic & & 0.41 & 0.25 & 0.14 & 0.22 & 0.33 \\
Investigative & 0.41 & & 0.36 & 0.25 & 0.30 & 0.19 \\
Artistic & 0.25 & 0.36 & & 0.34 & 0.35 & 0.20 \\
Social & 0.14 & 0.25 & 0.34 & & 0.32 & 0.10 \\
Enterprising & 0.22 & 0.30 & 0.35 & 0.32 & & 0.34 \\
Conventional & 0.33 & 0.19 & 0.20 & 0.10 & 0.34 & \\
\hline
\end{tabular}

Note. $\mathrm{n}=1500$.

When Table 1 is examined, it was found that the correlations between Realistic and Investigative, Social and Artistic, Enterprising and Conventional dimensions are close. It is also found that the correlations between Realistic and Social, Artistic and Conventional, Investigative and Enterprising are lower than the relations between other types. 
As it was done in exploratory factor analysis, the interrelations between dimensions were examined on the second data set with which the confirmatory factor analysis was used. The correlations of the six dimensions by which the latent variables are represented were given in Table 2.

Table 2

Correlation Coefficients Between the Dimensions of Second Dataset

\begin{tabular}{lllllll}
\hline & Realistic & Investigative & Artistic & Social & Enterprising & Conventional \\
\hline Realistic & & 0.50 & 0.25 & 0.13 & 0.22 & 0.53 \\
Investigative & 0.50 & & 0.35 & 0.33 & 0.34 & 0.26 \\
Artistic & 0.25 & 0.35 & & 0.37 & 0.35 & 0.21 \\
Social & 0.13 & 0.33 & 0.37 & & 0.39 & 0.12 \\
Enterprising & 0.22 & 0.34 & 0.35 & 0.39 & & 0.32 \\
Conventional & 0.53 & 0.26 & 0.21 & 0.12 & 0.32 & \\
\hline
\end{tabular}

Note. $\mathrm{n}=741$

High correlations were revealed between the dimensions of Realistic and Investigative, Artistic and Social, Conventional and Realistic. On the other hand, low correlations were obtained between Realistic and Social, Artistic and Conventional, Enterprising and Conventional dimensions.

For a better understanding of the findings involving inter-scale correlations of VII, these findings were shown on the hexagonal pattern of Holland in Figure 2. Figures given in the Table 1 were obtained correlations by using first data set $(n=1,500)$ and SPSS 15.0 statistic package software, and the figures given in the Table 2 were obtained correlations by using second data set $(\mathrm{n}=741)$ and LISREL 8.80 statistic package software.

Considering the correlations in figure, it is understood that the Holland's model is substantially valid for the research sample. For both data sets, the highest correlations were shown with the adjacent dimensions. As an example; for the first data set, it is found that the highest correlation of the Realistic type was with the adjacent dimensions Investigative (0.41) and Conventional (0.33), whereas the lowest correlation (0.14) was with the more distant Social dimension.

While the inter-scale correlations were revealed, it was seen that Enterprising type is having close correlations with the most of the other dimensions. A similar finding was also revealed with the O*NET Interest Inventory and it was found that the Enterprising type is having close correlations with other dimensions (Harrington \& Feller, 2004). This situation may be due to the competitive structure of the Enterprising types. Since current working environments require to be competitive and individuals feel that they need to have competencies, knowledge, and skills in multiple areas. This effort is at most in the lives of Enterprising type individuals and for this reason they may have given elevated-profilestyle responses to the items. Nevertheless, as it is stated above, the sample of VII mostly consists of individuals from Social and Enterprising types. Then structure of the sample may be an explanation for this situation. For similar scales based on the Holland's theory, there are similar little differences in the structure of the RIASEC dimensions. Rounds and Tracey (1993) reported that differences related with the structure of RIASEC based interest inventories may be arisen from the items of the scales and the sample structure may be as strong as the real reason of these differences. Sample structure may affect the range of scores and this situation may change the correlation values and the structure of the RIASEC pattern as well. As an example for a sample consisting of the psychology students, the range of Realistic scores may be quite low and due to this, the relation of the factor linked to the Realistic type between the other factors linked to other types and the general structure of the RIASEC may vary. 


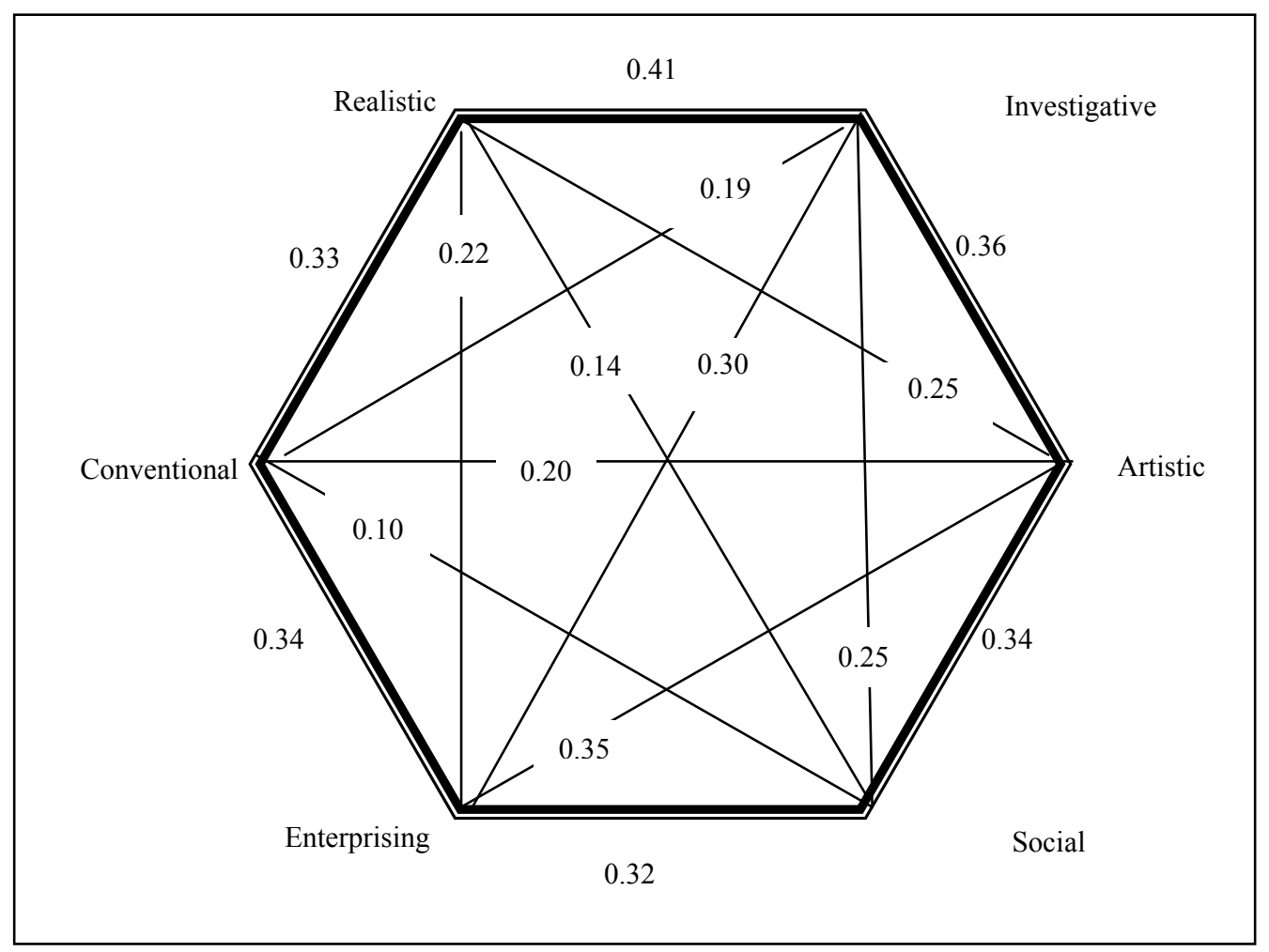

Figure 2. Interrealions of the VII dimensions on the hexagonal model of Holland.

\section{Conclusion}

In this research, it is aimed to estimate the validity of the Holland's personality theory on the sample by predicating findings upon the validity of VII which was developed on anadult sample. Based on the findings of this study, the personality types of Holland's theory were shown on a hexagonal model in accordance with the theoretical structure.

As it was revealed with other studies on this subject, it was found that the personality types that Holland theorizated show some differences in different cultural structures. In the light of the results, it is the fact that, there is a need of qualitative and quantitative studies to determine that whether the Social personality type and if interest assessment should include the activities related with the "helping" property or not and if should; to what extent, and to determine that this property falls into to scope of "interests" or "values". Furthermore, re-evaluation of another one of the personality types of Holland, "Enterprising" type would be helpful by considering the changing work environments and expected dynamic and flexible skills of the employees. As it is stated in this study, in the evaluation process of such self-assessment tools in which the scales, opened to social desirability defaults, are used, the competitive characteristics of the enterprising types cause partially uncertainties in the process of determination of the differences between dimensions.

The most significant limitation of this study is its relatively homogeneous sample structure. It can be said that this limitation has arisen from the reason that the individuals of the sample have been working in the same institution. In addition, since the number of women participant was low, the differences between genders were excluded from the scope of this study. As Osborn and Zunker (2006) stated before, a troubleshooting solution for the issues related with the differences between genders is the unisex structure of interest inventories which 
involves separate items representing the activities for both genders. Even though, this issue has been considered in particular duringitem development phase, there is still a need of similar studies among heterogeneous sample to evaluate the cultural validity of the Holland's theory by including the gender variation.

Consequently, after examining theinter-scale correlations of VII, it can be concluded that the hexagonal model of Holland is valid for sample of this study. This finding is also meaningful considering two different data sets and statistical methods being used in research. Correlations between the dimensions of the VII support largely the hexagonal model of Holland and it can be said that this theory is also valid for the administered Turkish sample on which the inventory was developed.

\section{References}

Armstrong, P. I., Allison, W., \& Rounds, J. (2008). Development and initial validation of brief public domain RIASEC marker scales. Journal of Vocational Behaviour, 73, 287-299.

Balkış, M. (2004). Adaptation of self-directed search in Turkish culture. Eurasian Journal of Educational Research, 17, 54-63.

Çokluk, Ö., Şekercioğlu, G., \& Büyüköztürk, Ş. (2010). Sosyal bilimler için çok değişkenli istatistik: SPSS ve LISREL uygulamaları. Ankara: Pegem Akademi.

Darcy, M. U. A. (2005). Examination of the structure of Irish students' vocational interests and competence perceptions. Journal of Vocational Behavior, 67, 321-333.

Elosua, P. (2007). Assessing vocational interests in the Basque Country using paired comparison design. Journal of Vocational Behavior, 71, 135-145.

Farh, J., Leong, F. T. L., \& Law, K. S. (1998). Cross-cultural validity of Holland's model in Hong Kong. Journal of Vocational Behavior, 52, 425-440.

Flores, L. Y., Spanierman, L. B., Armstrong, P. I., \& Velez, A. D. (2006). Validity of the strong interest inventory and skills confidence inventory with Mexican American high school students. Journal of Career Assessment, 14(2), 183-202.

Gottfredson, G. D., \& John L. (1999). Holland's contributions to vocational psychology: A review and evaluation. Journal of Vocational Behaviour, 55, 15-40.

Gupta, S., Tracey, T. J. G., \& Gore Jr., P. A. (2008). Structural examination of RIASEC scales in high school students: Variation across ethnicity and method. Journal of Vocational Behavior, 72, 1-13.

Harrington, T. F., \& Feller, R. W. (2004). Facilitating career development, assessment and interpretation practices. In J. E. Wall and G. R. Walz (Eds.)., Measuring up: Assessment issues for teachers, counselors, and administrators (pp. 581-593). Texas: PRO-ED Inc.

Hedrih, V. (2008). Structure of vocational interests in Serbia: Evaluation of thespherical model. Journal of Vocational Behavior, $73,13-23$.

Holland, J. L. (1997). Making vocational choices: A theory of vocational personalities and work environments (3rd ed.). Florida: PAR Inc.

Holland, J. L.,Whitney, D. R., Cole, N. S., \& Richards Jr., J. M. (1969). An emprical occupational classification derived from a theory of personality and intended for practice and research (ACT Research Report No: 29). Iowa: ACT R \& D Division.

Kuzgun, Y. (2003). Kendini Değerlendirme Envanteri el kitabı. Ankara: ÖSYM Yayınları.

Laurence, J. H. (2004). Test consumers in themilitary: Use of themilitary career exploration program in schools. In J. E. Wall ve and G. R. Walz (Eds.), Measuring up: Assessment issues for teachers, counselors, and administrators. Texas: PRO-ED Inc.

Leong, F. T. L., Austin, J. T., Sekaran, U., \& Komarraju, M. (1998). An evaluation of the cross-cultural validity of Holland's theory: Career choices by workers in India. Journal of Vocational Behavior, 52, 441-455.

McClain, M. C., \& Reardon, R. (2015). The U.S. workforce from 1960 to 2010: A RIASEC view. The Professional Counselor, 5(1), 1-14.

Nagy, G.,Trautwein, U., \& Lüdtke, O. (2010). The structure of vocational interests in Germany: Different methodologies, and different conclusions. Journal of Vocational Behavior, 76, 153-169.

Osborn, D. S., \& Zunker, V. G. (2006). Using assessement results for career development (7th ed.). CA: Brooks/Cole.

Özyürek, R. (1996). Üniversite öğrencilerinin Öğrenci Yerleştirme Sınavı'ndaki puan türleri ile Kendini Değerlendirme Envanteri'nin puanları arasındaki ilişki. Psikolojik Danışma ve Rehberlik Dergisi, 2(9), 25-32. 
Primavera, M. T., Church, A. T., \& Katigbak, M. S., et. al. (2010). The structure of vocational interests in Filipino adolescents. Journal of Vocational Behavior, 77, 213-226.

Reardon, R. C., \& Lenz, J. G. (1999). Holland's theory and career assessment. Journal of Vocational Behavior, 55, 102-113.

Rounds, J., \& Tracey, T. J. (1993). Prediger's dimensional representation of Holland's RIASEC circumplex. Journal of Applied Psychology, 7(6), 875-890.

Savickas, M. L., \& Gottfredson, G. D. (1999). Holland's theory (1959-1999): 40 years of research and application. Journal of Vocational Behavior, 55, 1-4.

Schermelleh-Engel1, K., Moosbrugger, H., \& Müler. H. (2003). Evaluatingthe fit of structural equation models: Tests of significance and descriptive goodness-of-fit measures. Methods of Psychological Research Online, 8(2), 23-74. Retrieved from http://user.uni-frankfurt.de/ kscherm/schermelleh/mpr_Schermelleh.pdf

Sverko, I., \& Babarovic, T. (2006). The validity of Holland's theory in Croatia. Journal of CareerAssessment, 14(4), 490-507.

Sverko, I. (2008). Spherical model of interests in Croatia. Journal of Vocational Behavior, 72, 14-24.

Şimşek, Ö. F. (2007). Yapısal eşitlik modellemesine giriş: temel ilkeler ve LISREL uygulamaları. Ankara: Ekinoks.

Tabachnick, G. G., \& Fidel, L. S. (2001). Using multivariate statistics (4th ed.). MA: Allyn \& BaconInc.

Tang, M. (2008). Examining the application of Holland's theory to vocational interests and choices of Chinese college students. Journal of Career Assessment, 17(1), 86-98.

Tracey, T. J. G., \& Gupta, S. (2008). Interest assessment in an international context. In J. A. Athanasou and R. Van Esbroeck (Eds.), International handbook of career guidance (pp. 525-537). Springer Science and Business Media B.V.

Tracey, T. J. G., \& Rounds, J. (1995). Thearbitrary nature of Holland's RIASEC types: Aconcentric-circles structure. Journal of Counseling Psychology, 42(4), 431-439.

Yang, W., Lance, C. E., \& Hui, H. C. (2006). Psychometric properties of the Chinese self-directed search (1994 ed.). Journal of Vocational Behavior, 68, 560-576.

Yang, W., Stokesa, G. S., \& Hui, C. H. (2005). Cross-cultural validation of Holland's interest structure in Chinese population. Journal of Vocational Behavior, 67, 379-396.

Yeşilyaprak, B. (2005). Ĕgitimde rehberlik hizmetleri (11. bs.). Ankara: Nobel Yayın Dağıtım.

Yıldırım, E. (2001). Akademik liselerdeki alan türlerine uygun olan ABKÖ altölçeklerin in Holland'ın altıgen modelinden yararlanılarak belirlenmesi (Unpublished master's thesis). Çukurova Üniversitesi, Adana.

Y1lmaz, O. (2011). Mesleki İlgi Envanterinin Geliştirilmesi (Unpublished master's thesis). Hacettepe Üniversitesi, Ankara. 